\title{
New species and morphological notes on the termitophilous genera Fonsechellus Silvestri and Oecidiophilus Silvestri from Brazil (Staphylinidae, Aleocharinae, Corotocini, Termitoceina)
}

\author{
Bruno Zilberman' \& Luiz Roberto Fontes ${ }^{2}$ \\ 1 Universidade de São Paulo (USP), Museu de Zoologia (MZUSP). São Paulo, SP, Brasil. \\ ORCID: http://orcid.org/0000-0003-2613-4827. E-mail: brunozilberman@usp.br \\ 2 Independent researcher. São Paulo, SP, Brasil. ORCID: http://orcid.org/0000-0002-3872-9003. E-mail: Irfontes@uol.com.br
}

\begin{abstract}
Fonsechellus Silvestri and Oecidiophilus Silvestri consist of two Neotropical genera of termitophilous rove beetles, which have been poorly characterized due to the scarcity of material for studies. Herein, based on material collected in the seventies and housed in the Museu de Zoologia da Universidade de São Paulo, two new species associated with Atlantitermes guarinim Fontes and Diversitermes sp., are described and illustrated: Fonsechellus heterosetosus sp. nov. and Oecidiophilus cleidecostae sp. nov., respectively. The latter represents the first record of the genus to Brazil. Also, Fonsechellus fragilis and F. fontesi are redescribed, and a key for species identification is provided for the genus. The condition of the membranous wings of Fonsechellus is addressed and discussed, and the definition of both genera is expanded.
\end{abstract}

Key-Words. Termitophily; Neotropical; Rove Beetles; Chaetotaxy; Wing Loss.

\section{INTRODUCTION}

The subtribe Termitoceina was established in a monograph on Corotocini by Jacobson et al. (1986) to group six genera presenting tarsal formula 5-5-5 and barely sclerotized paratergites, and also having the same generalized head and thoracic features found in the subtribe Abrotelina. These six genera were established by Silvestri, mostly in a paper published in 1946 (Fonsechellus, Mormellus, Oecidiophilus, Parvidolum and Perlinctus), and Termitoiceus, in an earlier paper (Silvestri, 1901).

Historically, the relationships among the Termitoceina genera were surrounded by uncertainty due to the scarcity of material for dissection, resulting in the lack of detailed morphological studies. The genus Fonsechellus Silvestri, 1946 was established along with the description of two species: F. bicolor and F. diversicolor. The author also divided the genus into two subgenera (Fonsechellus s. str. and Trianellus) based on the ratio of head length and width, their head chaetotaxy, and also on the presence or absence of geniculate bristles on sternites. Later, Seevers (1957) described Fonsechellus fragilis, also provid- ing morphological notes on the genus, redescription of the two former species and a key for their identification. Seevers (1957) criticized the previous division of the genus Fonsechellus and pointed out that the characters provided by Silvestri (1946) did not justify the establishment of the subgenera. Even though not explicity informed, Seevers treated Trianellus and Fonsechellus as possible synonyms. Nonetheless, Seevers did not provide further details about the problems of Silvestri's characters, and later on, Kistner (1993) interpreted Seevers' approach as if he had in fact synonymized Trianellus with Fonsechellus. Kistner, in the same paper, described Fonsechellus fontesi based on specimens collected and sent to him by LR Fontes. Kistner (o. c.) also provided keys for species and a hypothesis of relationships for most genera of the subtribe.

Oecidiophilus Silvestri, 1946 is a more enigmatic genus represented by only one species, Oecidiophilus mimellus Silvestri, 1946, from Loreto (Misiones, Argentina). No subsequent information has been published due to rarity of this species in collections.

Herein, a new species of Fonsechellus, F. heterosetosus sp. nov. is described, and F. fragilis 
Seevers, 1957 and F. fontesi Kistner, 1993 are redescribed. A key for species identification is also provided. Additionally, a second species of Oecidiophilus, O. cleidecostae sp. nov., is also described. This species represents the first record of the genus for Brazil, expanding its geographical distribution. This new species is rather distinct, supporting its taxonomic validation, but known by only one specimen from Brazil, Minas Gerais (Belo Horizonte) and a more detailed description is impossible without proper dissection.

\section{MATERIAL AND METHODS}

Dissection and illustration procedures follow Zilberman (2018), with adaptation on specimens mounting on slides, now with glycerin jelly. Terminology follows Jacobson et al. (1986) for external and internal morphology and Sawada (1972) for chaetotaxy of sternite VIII, labrum and postmentum, with the following modification to postmentum chaetotaxy: although the three main bristles approached by Sawada were definitely present, it was not possible to have the homology inferred. Thus, we decided to use an alternative, provisory terminology based on the length of bristles: long $(I)$, medium $(m)$ and short (s).

The specimens studied are deposited at the Museu de Zoologia da Universidade de São Paulo (MZSP).

\section{Fonsechellus Silvestri, 1946}

Fonsechellus Silvestri, 1946:312.Type species:Fonsechellus diversicolor Silvestri, by original designation.

Trianellus Silvestri, 1946: 315 (subgenus); Seevers, 1957: 130 (suggested synonym); Kistner, 1993: 201 (synonym). Type species: Fonsechellus (Trianellus) bicolor Silvestri, by monotypy.

Diagnosis: Physogastric and small species, usually less than $2 \mathrm{~mm}$ long, sclerotized parts reddish-brown to pale yellow, paratergites separated and barely sclerotized. Tarsal formula 5-5-5, two spurs at apex of anterior tibia and one at apex of median tibia. Tergites sclerotized into rectangular bands and sternites poorly sclerotized, and sides of third or fourth to sixth sternites with dense clusters of bristles, geniculate in some species. Chaetotaxy of pronotum and abdomen with interspecific variation in size and density; also variable between male and female in some species.

Redescription: Head slightly longer than wide, widest right before the eyes; gula straight; foramen magnum less than 2.5 times the head width; eyes circular in shape; front impressed; antenna with 11 antennomeres: scape elongate, antennomeres II-X subquadrate, XI oblong, with proximal margin transverse. Mentum fused to submentum (postmentum), subtrapezoidal, lateral margins evenly round; position of the three main bristles near apex variable interspecifically. Prementum subquad- rate, labial palpi with 3 palpomeres, ligula broad, bilobed apically in most species. Mandibles asymmetrical; right mandible with longitudinal row of small teeth on cutting edge; both mandibles bear a median tooth, conspicuously larger on left mandible, and a drop-shaped sulcus on lateral margin. Maxillae with stipites longer than wide, each bearing three long bristles: two on posterior region on either side next to cardo, and another next to the palpifer; galea about as long as lacinia, subquadrate with many short bristles; palpi with 4 palpomeres, first palpomere small, subquadrate; second palpomere elongate and about three times longer than the second; third palpomere slightly longer than the second; fourth narrow, about twice as long as the first. Labrum transverse in most species, with $p 1, m 2-m 1$ and at least one bristle of $d$ row present; most species with conspicuous pairs of median rows of bristles.

Thorax: Pronotum about as long as wide, widest on anterior margin, which is slightly convex; chaetotaxy variable. Wings present and broken. Elytra setose, about 1.5 times longer than wide and lateral margins straight in most species. Mesosternum slightly shorter and narrower than metasternum; endosternite with slender arms, about 1.5 times longer than the base. Legs well developed; anterior tibia with two internal apical spurs and median tibia with one.

Abdomen highly physogastric with generalized pattern shape; segment I with a narrow tergite with medial margin projected backwards; segment II with one tergite and paratergites, the latter as sclerotized diagonal bands; paratergites of remaining segments barely sclerotized. Segments III-VIII each with complete tergite and sternite; tergites expanded posteriorly with secondary sclerotization; sternites represented by weakly sclerotized bands, sometimes barely visible; rows of bristles present on tergites and sternites, with length varying between species or even between male and female within a same species; sternite VIII wider than long, with six main bristles: a row of four bristles on median region and another row with two; the distance between the two rows vary between male and female, being closer in the latter; tergite VIII subquadrate, with two pairs of long bristles on median region (a2-a1), three to four pairs of medium-sized bristles present apically (p3-p2-p1/ $p 4-p 3-p 2-p 1)$; distance of each side a1 bristle vary between male and female, being closer on the latter; sternite IX in females divided into two slender pieces attached to margins of tergite IX; sternite IX in males in one piece shovel-shaped apically and variable chaetotaxy among species; tergite IX with long apodemes in males and many small-medium size bristles; a distinct long bristle is present in most species; tergite $X$ subquadrate with chaetotaxy variable, two pairs of long bristles on either side and a central bristle of same size is a condition present in most species. Aedeagus bulbous with shape of median lobe apex variable in some species. Spermatheca with capsule and stem sclerotized, shaped similarly among species. 
Host relationship: Fonsechellus species were found living in association with one the following termite genera or species: Velocitermes Holmgren, Diversitermes Holmgren, Subulitermes Holmgren, Atlantitermes guarinim Fontes, 1979, and Araujotermes caissara Fontes, 1982.

Remarks: Fonsechellus species are often compared to those of Termitoiceus (Silvestri, 1901; Seevers, 1957; Kistner, 1993) due to overall body shape. Silvestri (1901) distinguished members of Fonsechellus in having a bilobed ligula, macrosetae on tergite IX and geniculate setae on sternites IV-VII. Additional differences from Termitoiceus pointed out by Kistner (1993) are related to the shapes of the labial palps, pronotum, elytra, meso- and metasternum, meso- and metanotum, mandibular teeth, galea, tarsi, and sclerotization of tergites and paratergites, as well as the shape of lateral lobe of aedeagus and connection of gland reservoir of abdominal segment VII.

The degree of sclerotization of tergites, sternites and parategites, mild in Fonsechellus and heavy in Termitoiceus, is probably the most conspicuous difference at first glance. Some species of Fonsechellus do not have geniculate bristles on sternites, bilobed ligula or macrosetae on tergite IX. The presence of mandibular sulcus on lateral margin, longitudinal row of small teeth present near apex of right mandible, sexual dimorphism of chaetotaxy (a1 bristles) of tergite VIII, and shovel-shaped apex of sternite IX (male), could be considered as generic characteristics, but a broader study of other genera in Termitoceina is needed for confirmation. Other characteristics present
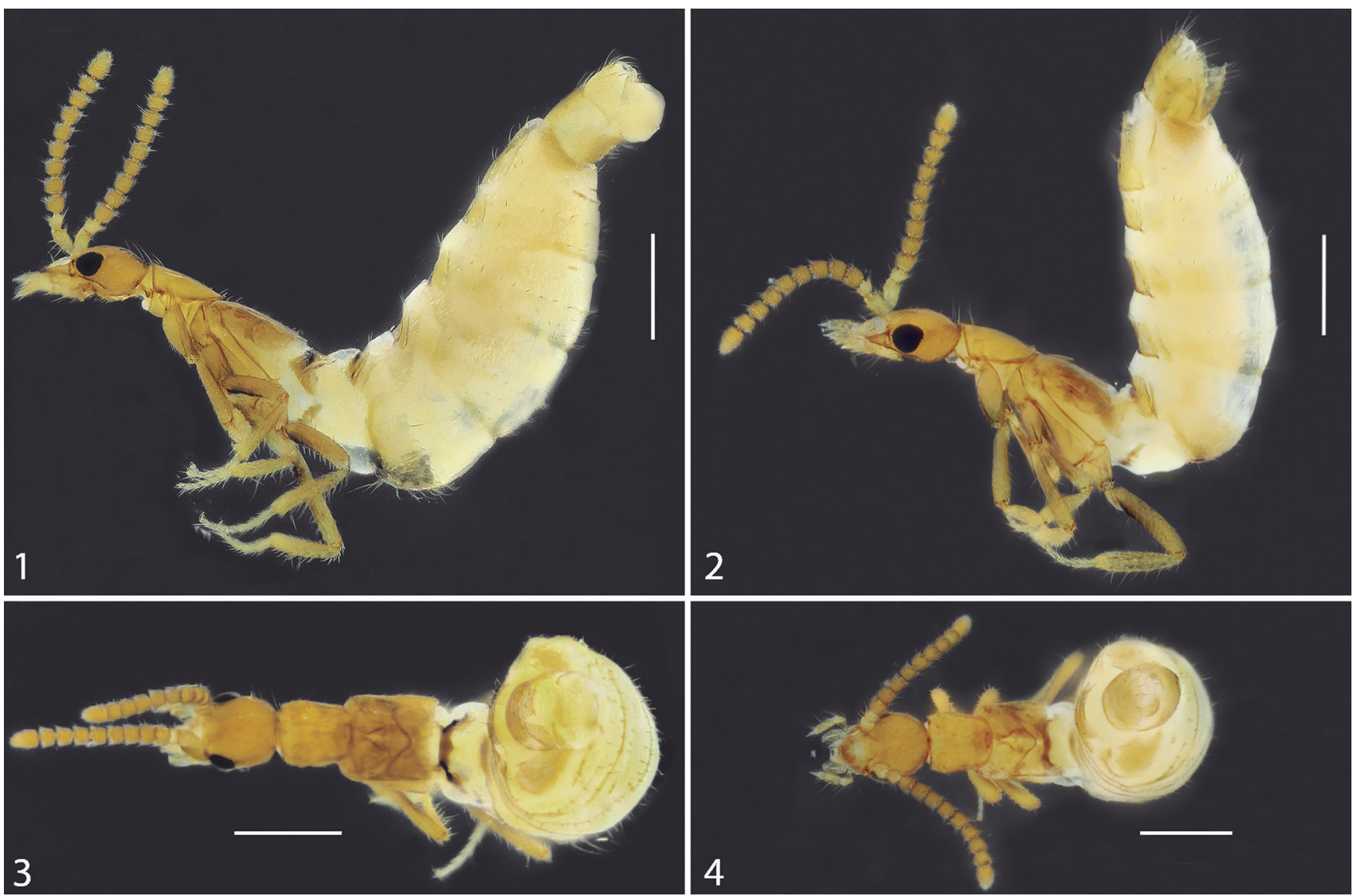

in most species (except F. fontesi, discussed later in this paper) are bilobed ligula, distinct macrosetae on tergite IX and conservative chaetotaxy for tergite $\mathrm{X}$.

\section{Key to Fonsechellus species}

1. Tibiae heavily sclerotized (see Kistner, 1993 figs. 1a-1c). Associated with Velocitermes sp. or Diversitermes sp...................... F. diversicolor Silvestri

1.' Tibiae moderately sclerotized (see Kistner, 1993 figs. 1a-1c)....................2

2. Sclerotized parts pale yellow. Labrum swollen in lateral view (Figs. 25, 26). Associated with Araujotermes caissara Fontes................. fontesi Kistner

2. Sclerotized parts darker, yellowish to reddish. Labrum not swollen in lateral view.

3. Bristles on the sides of the abdomen, especially in segment $\mathrm{VI}$, with straight, non-geniculate tips.

3'. Bristles on the sides of the abdomen, especially in segment $\mathrm{VI}$, with geniculate tips (see Silvestri, 1946, figs. 14, 16). Associated with Nasutitermes sp. (N. distinctellus, nomen nudum (Silvestri, 1946))........

...F. bicolor Silvestri

4. Male and female with short bristles on abdomen. Pronotum with four macrosetae: two on disk near apex and two marginal; discal setae closer together than those of marginal. Associated with Subulitermes sp........

F. fragilis Seevers

4'. Female with long bristles on abdomen; male similar in general aspect to male or female of $F$. fragilis. Pronotum of female with 6 pairs macrosetae: two pairs on anterior margin near apical angle, two on each lateral margin, one subapical pair and another pair near base. Associated with Atlantitermes guarinim Fontes...

F. heterosetosus sp. nov.

Figures 1-4. Fonsechellus fragilis Seevers, 1957. Habitus, lateral: (1) female; (2) male. Habitus, dorsal: (3) female; (4) male. Scale bars: $0.4 \mathrm{~mm}$. 


\section{Fonsechellus fragilis Seevers \\ (Figs. 1-24, 64, 67, 68, 73-77)}

Fonsechellus fragilis Seevers, 1957: 131.

Material examined: BRAZIL. Santa Catarina: Itapema, 21.vii.1978, Renato L. de Araujo \& Luiz R. Fontes col., 7 specimens (2 dissected on slides) (MZSP 21165) (with Subulitermes sp., MZSP 7683).

Type locality: BRAZIL. Santa Catarina: Blumenau.

Measurements: Length 1.5-1.7 mm (abdomen shrunk).

Diagnosis: Sclerotized parts light yellow, labrum not swollen; male and female scarcely setose, with short bristles on abdomen; pronotum of male and female with only four primary bristles.
Redescription: Head almost as long as wide, widest just behind the eyes (Fig. 5), with scattered bristles on dorsal and ventral views, and a pair of long bristles on dorsal posterior region. Labrum transverse, about 1.7 times wider than long, not swollen in lateral view; bristles $d 2$ / $m 2-m 1 / p 1$ present in male and female, $d 1$ present in female; three pairs of bristles present on the longitudinal-medial region of labrum, one of which, near base, is absent in female (Figs. 10, 67). Mentum with four bristles each side, three reconizable primary bristles, near apex, long $(l)$, medium $(m)$ and short $(s)$, distributed as follows: $m$ on anterior region, followed by / located next to the sides, out of the longitudinal row of $m$; and more posterior, $s$ located on longitudinal row of $m$; a short bristle located between $m$ bristles is present on female (Fig. 68).

Thorax: Pronotum with four primary bristles, two on anterior margin and two on disk near apex, these closer to
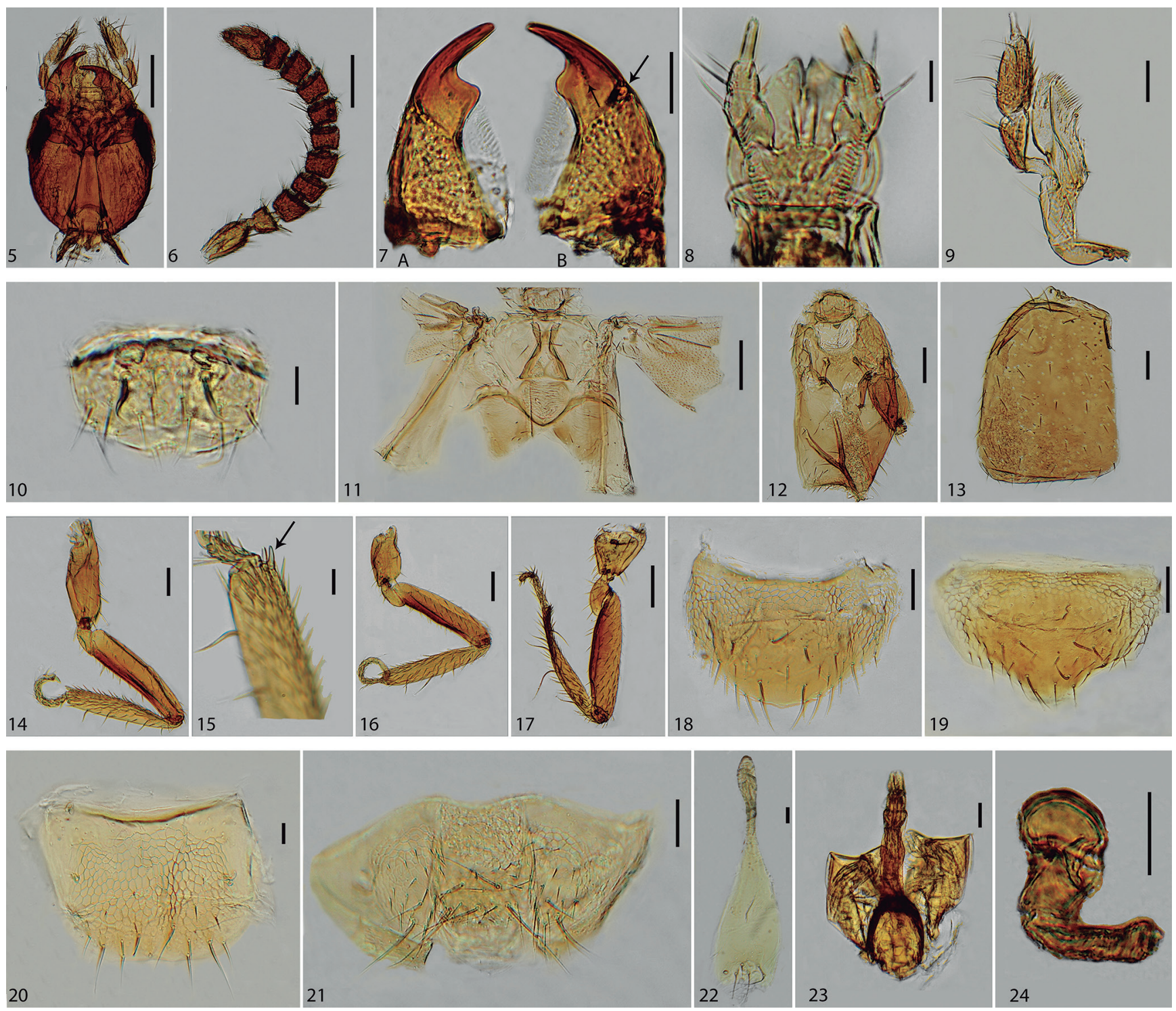

Figures 5-24. Fonsechellus fragilis Seevers, 1957. (5) Head, ventral; (6) antenna; (7A, B) mandible, left and right, arrows indicate teeth and drop shaped sulcus; (8) prementum; (9) maxilla; (10) labrum; (11) meso and metanotum; (12) meso and metasternum; (13) elytron; (14) anterior leg; (15) anterior tibia, with arrow indicating spurs; (16) middle leg; (17) hind leg; (18) sternite VIII (female); (19) sternite VIII (male); (20) tergite VIII (female); (21) tergites IX and X (female); (22) sternite IX (male); (23) aedeagus; (24) spermatheca. Scale bars: 8, 10, 15, 22 =0.02 mm; 9, 20, $24=0.03 \mathrm{~mm} ; 7 \mathrm{a}, 7 \mathrm{~b}, 13,23=0.04 \mathrm{~mm} ; 21=0.05 \mathrm{~mm} ; 18=0.06 \mathrm{~mm}$; $11,12,19=0.07 \mathrm{~mm} ; 14=0.08 \mathrm{~mm} ; 16=0.09 \mathrm{~mm} ; 5,17=0.11 \mathrm{~mm} ; 6=0.13 \mathrm{~mm}$. 
each other than the marginal pair; elytra slightly elongate; considering the widest and longest measurements, about 1.3 times as long as wide (Fig. 13).

Abdomen with short bristles in male and female (Figs. 1-4); tergite VIII with two pairs of transversally misaligned long bristles on median region (a2-a1), three pairs of medium sized apical bristles ( $p 3-p 2-p 1)$ and a similar-sized pair present between the median and apical row of bristles (Figs. 20, 73, 74); sternite VIII with three pairs of transversally misaligned primary long bristles on median row and two long bristles centered next to apex (Figs. 18, 19, 75, 76); sternite IX in females divided into two slender pieces attached to each margin of tergite IX (Fig. 21); sternite IX in males with apex enlarged; three apical primary long bristles, and two shorter bristles more distant from apex (Fig. 22); tergite IX with many medium-sized and short bristles, and one long and one very long bristles; tergite $X$ with two pairs of long bristles on either side and a central bristle of same size (Fig. 21). Aedeagus with median lobe apex not extended anteriorly on dorsal region (Figs. 23, 64).

\section{Host relationship: Associated with Subulitermes sp.}

Distribution: BRAZIL. Santa Catarina: Blumenau (type locality), and Itapema.
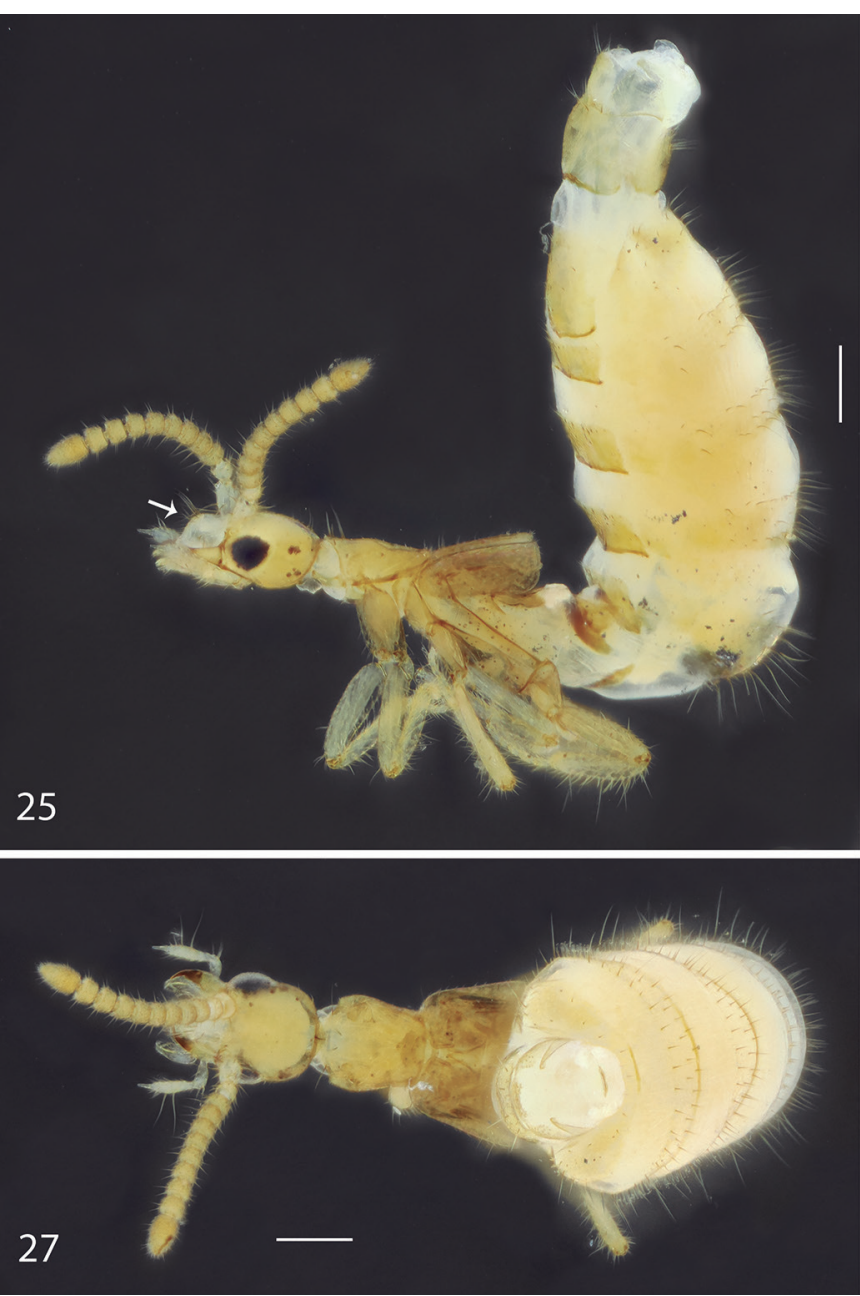

Remarks: Seevers (1957) compared this species with F. bicolor, from which is distinguished by the chaetotaxy of pronotum (four bristles instead of ten) and the presence of non-geniculate bristles on sternite VI. Probably, the most conspicuous character to differentiate $F$. fragilis from $F$. bicolor is the presence of short bristles on the abdomen of the former species, whereas they are mostly long in the latter. It is noteworthy that the information in Kistner's (1993) key that $F$. fragilis has geniculate bristles is incorrect. In the key, the number of bristles on the pronotum of F. bicolor is said firstly to be eight, but in the following line, when the chaetotaxy is detailed, the total is precisely ten, even though the correct number is 12 (Silvestri, 1946, see fig. 8).

Although the tergites seem to have three pairs of primary bristles on apex (p3-p2-p1), similarly to Fonsechellus heterosetosus sp. nov., there is an additional pair of medium-sized bristles (same size of $p$ row bristles) located between $a$ and $p$ rows. This last pair is possibly homologous to the fourth bristle ( $p 4)$ of F. fontesi, with the difference that in the latter it is aligned to the other bristles of the same row.

\section{Fonsechellus fontesi Kistner, 1993: 204.}
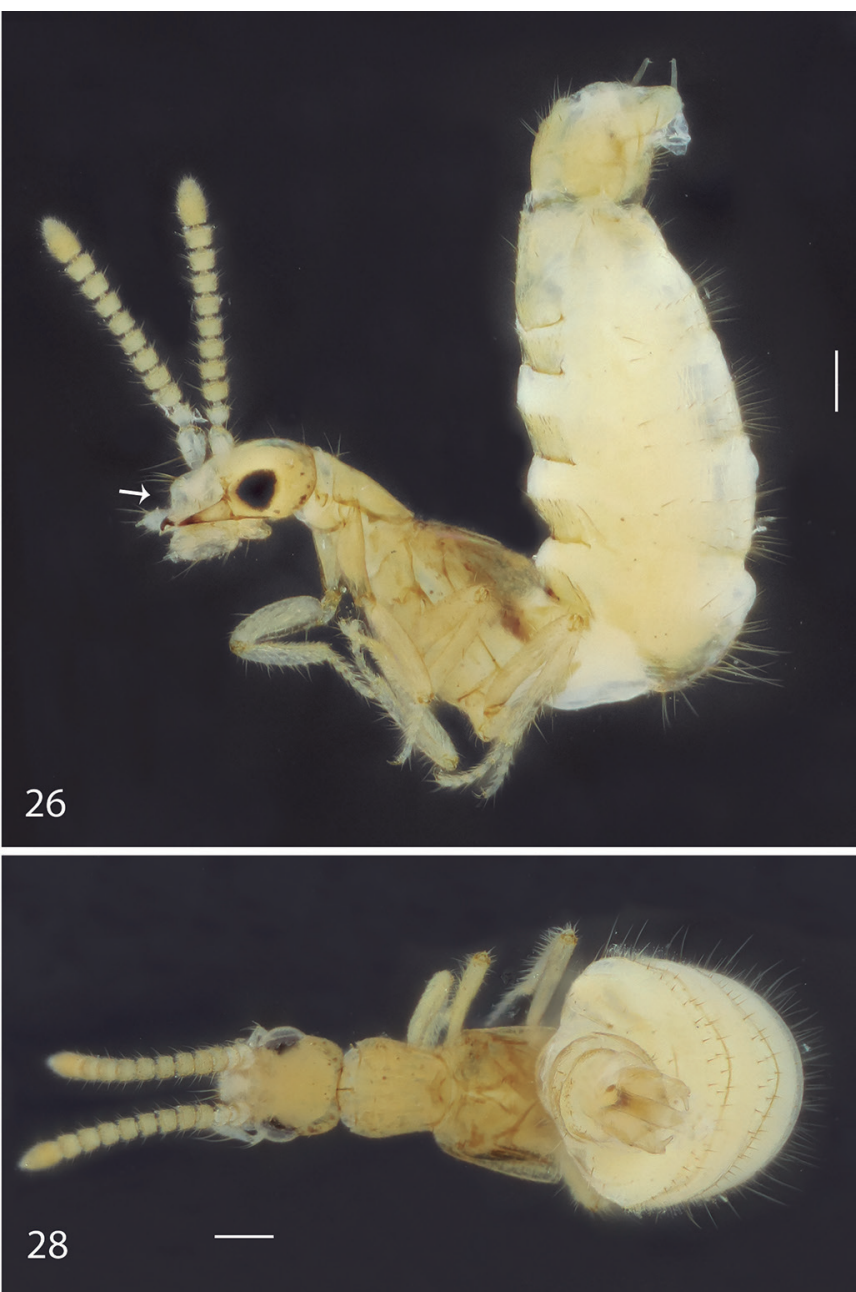

Figures 25-28. Fonsechellus fontesi Kistner, 1993. Habitus, lateral: (25) female, with arrow indicating the swollen labrum; (26) male, with arrow indicating the swollen labrum. Habitus Dorsal: (27) female; (28) male. Scale bars: $0.1 \mathrm{~mm}$. 
Type material examined: HOLOTYPE (ơ). BRAZIL. São Paulo: Itanhaém, Cidade Santa Júlia, 02.iv.1988, Luiz R. Fontes col. (MZSP 21255). PARATYPES. BRAZIL. São Paulo: Ubatuba, 26.xii.19864, Luiz R. Fontes col., 4 specimens (MZSP 21256-21259).

Additional material examined: BRAZIL. São Paulo: Itanhaém, Cidade Santa Júlia, 23-25.iii.1978, Luiz R. Fontes \& F.S. Berchez col. (with Araujotermes caissara, MZSP 7605), 1 specimen, (last segments of abdomen dissected on slides) (MZSP 21167); 29.vii-03.viii.1978, Luiz R. Fontes \& S.A. Marques col. (with Araujotermes caissara,
MZSP 7716) 3 specimens (1 dissected on slides) (MZSP 21169).

Measurements: Length 1.3-1.5 mm (abdomen shrunk).

Diagnosis: Sclerotized parts pale yellow; labrum unusually shaped, swollen in lateral view; female and male with long bristles on abdomen; pronotum of male and female with four bristles.

Description: Head almost as long as wide, widest right behind the eyes. Labrum peculiarly shaped, almost as
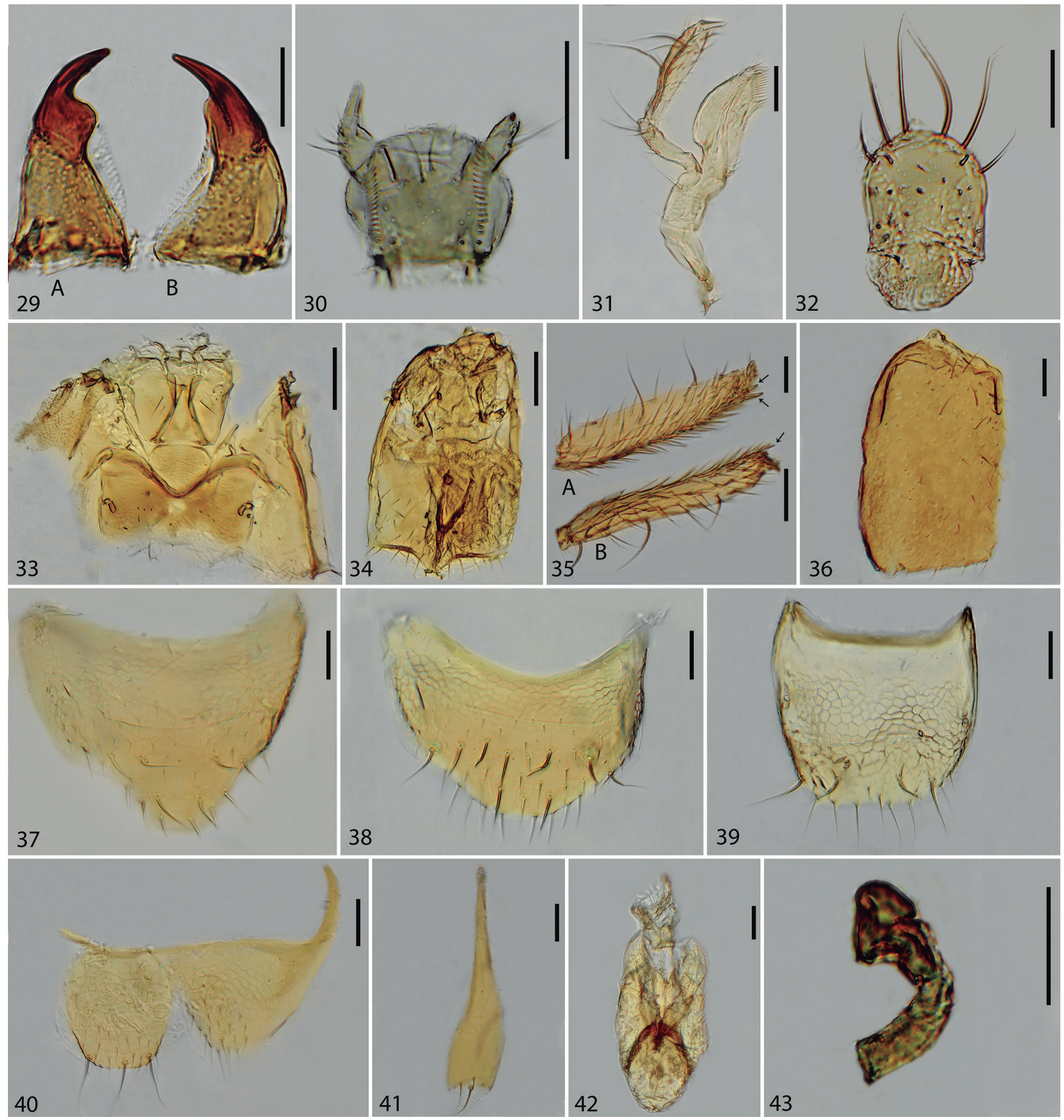

Figures 29-43. Fonsechellus fontesi Kistner, 1993. (29A, B) mandible, left and right; (30) prementum; (31) maxilla; (32) labrum; (33) meso and metanotum; (34) meso and metasternum; (35A, B) tibiae: anterior leg and median leg, arrows indicating spurs; (36) elytron; (37) sternite VIII (male); (38) sternite VIII (female); (39) tergite VIII (female); (40) tergites IX and X (male); (41) sternite IX (male); (42) aedeagus; (43) spermatheca. Scale bars: $0.05 \mathrm{~mm}$. 
long as wide; all primary bristles located on posterior region, which is projected upwards due to the truncated and swollen appearance of its attachment with head; one bristle of $d$ complex located on postero-central region; from apex to line of $d$ bristle, $p 1-m 1-m 2$ are evenly distributed on margins (Figs. 25, 26, 32, 69). Mentum with four bristles each side, three recognizable primary bristles, near apex, longitudinally aligned on margins, as follows: medium (m), long ( () , short (s) (Fig. 70).

Thorax: Pronotum similar to $F$. fragilis, with four bristles in male and female; elytra elongate: considering the widest and longest measurements, it is more than 1.6 times as long as wide (Fig. 36).

Abdomen with long bristles in male and female (Figs. 25-28); tergite VIII with two pairs of transversally aligned long bristles on median region (a2-a1), and four pairs of midsized apical bristles (p4-p3-p2-p1) (Figs. 39, 78, 79); sternite VIII with three pairs of transver- sally aligned primary long bristles on median row (slightly misaligned in female) and one pair of long bristles centered below (Figs. 37, 38, 80, 81); sternite IX in females divided into two slender pieces attached to each margin of tergite IX; sternite IX in male with posterior region slender, with four long apical bristles and one shorter above (Figs. 41, 82); tergite IX with many medium and short bristles; long and very long bristles absent; tergite $X$ with three apical long bristles (Fig. 40). Aedeagus with median lobe apex extended anteriorly on the dorsal region (Figs. 42, 65).

\section{Host relationship: Associated with Araujotermes} caissara.

Distribution: BRAZIL. São Paulo: Ubatuba (type locality) and Itanhaém; Santa Catarina: Piçarras.

Remarks: This species is the most distinct within the genus. The pale yellowish color, along with the oddly
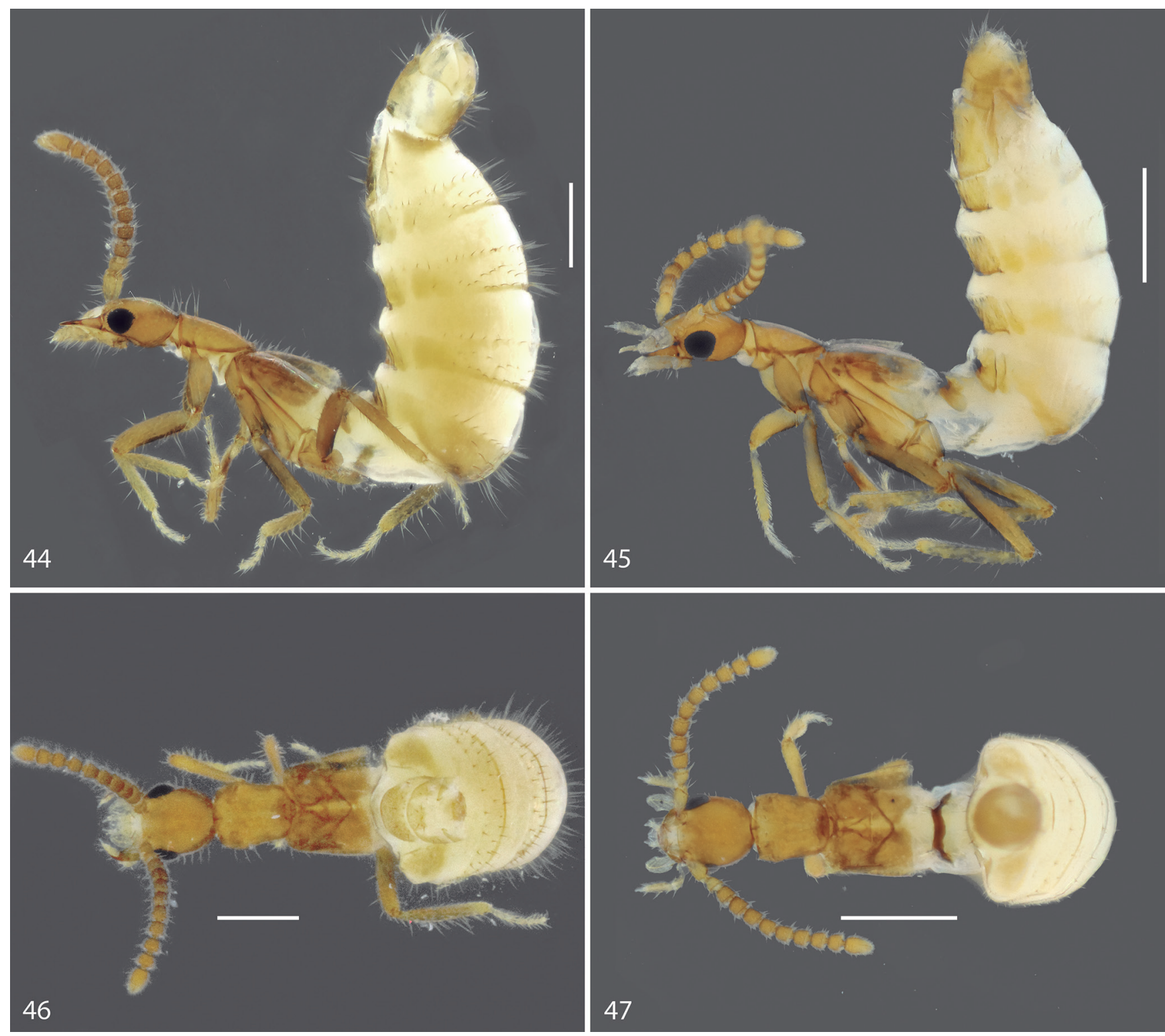

Figures 44-47. Fonsechellus heterosetosus sp. nov. Habitus, lateral: (44) female; (45) male. Habitus, dorsal: (46) female; (47) male. Scale bars: 0.4 mm. 
shaped and swollen labrum, easily distinguish it from any other species of Fonsechellus. Fonsechellus fontesi has the majority of common characters of the genus: shape of the median teeth of the mandibles and asymmetrical size of left and right mandibles; right mandible with a longitudinal row of small teeth; drop-shaped sulcus on the lateral margin of the mandibles; presence of spurs on the anterior and median tibiae; sexual dimorphism in the chaetotaxy of tergite VIII; and shovel-shaped apex of male sternite IX. Other characteristics that distinguish it from the other species include the labrum almost as long as wide and with distinct chaetotaxy, tergite $X$ with only three apical primary bristles, tergite IX without long bristles, and the male sternite IX with a narrow posterior region.

For now, we have decided to maintain F. fontesi in the genus, but future detailed studies on related genera may provide more evidence for transferring the species to a new genus.

\section{Fonsechellus heterosetosus sp. nov. \\ (Figs. 44-63, 66, 71, 72, 83-87)}

Type material: HOLOTYPE (\$, MZSP 21168): BRAZIL. São Paulo: Itanhaém, Cidade Santa Júlia, 26.iii.1979, Luiz R.
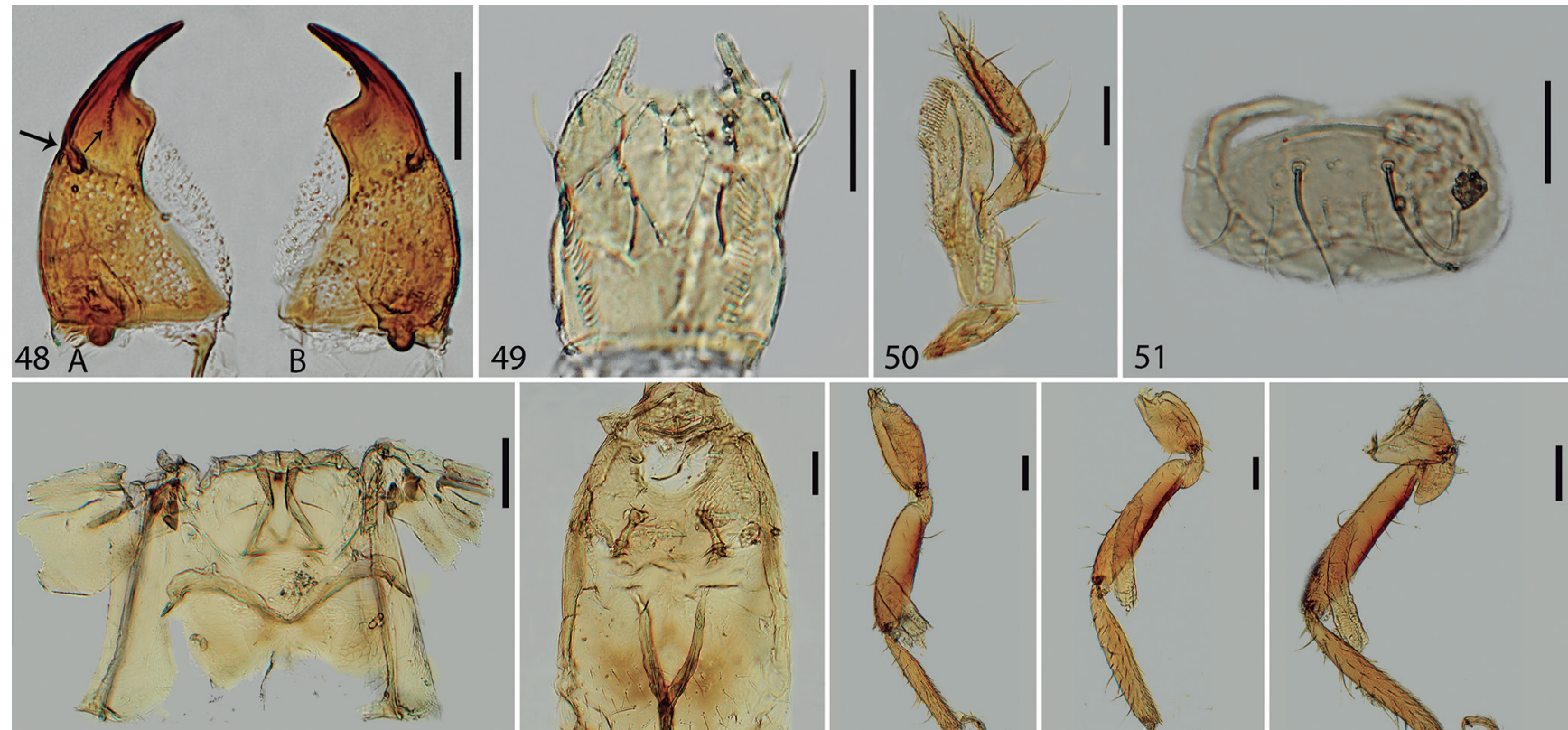

52
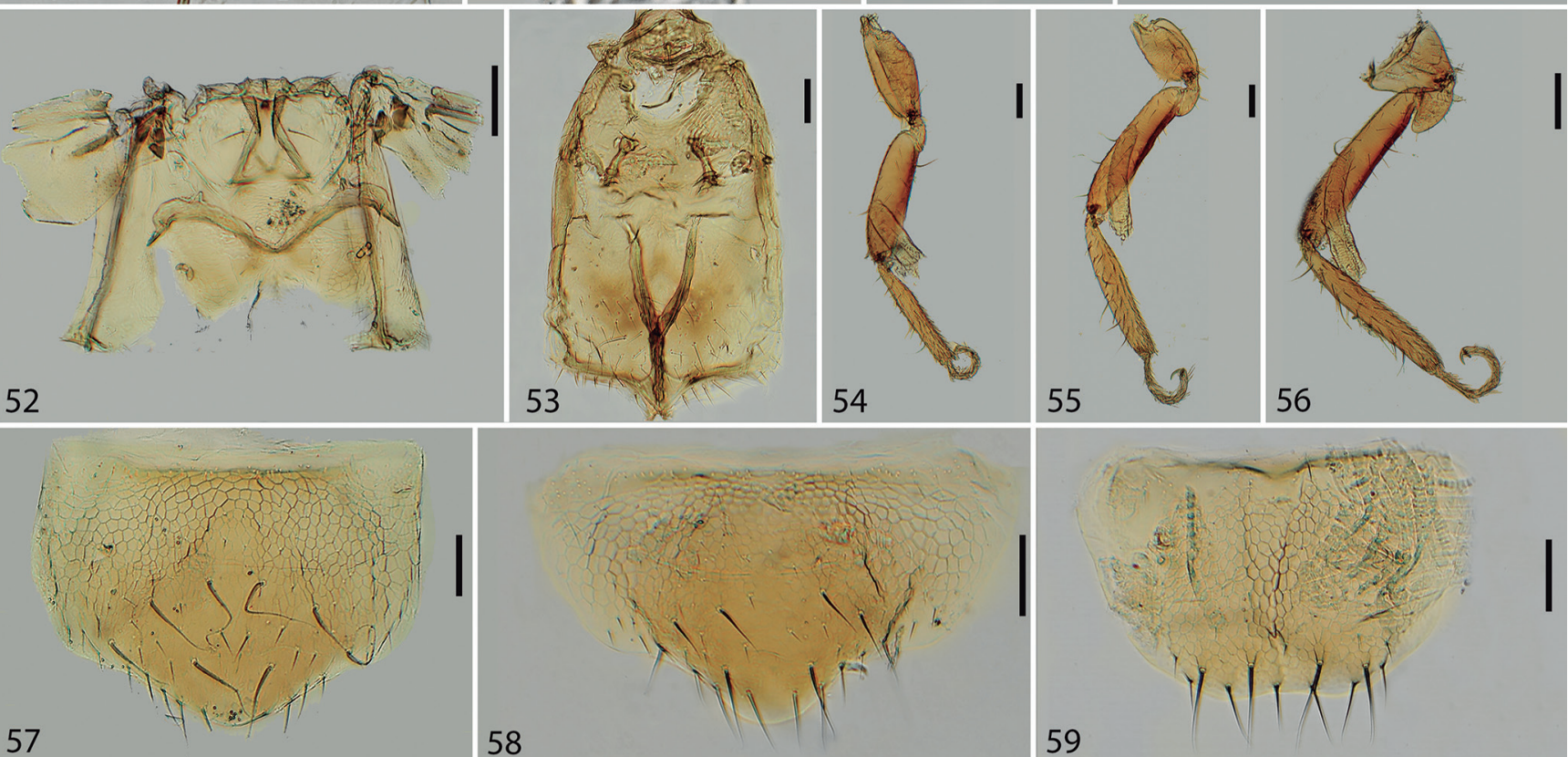

58
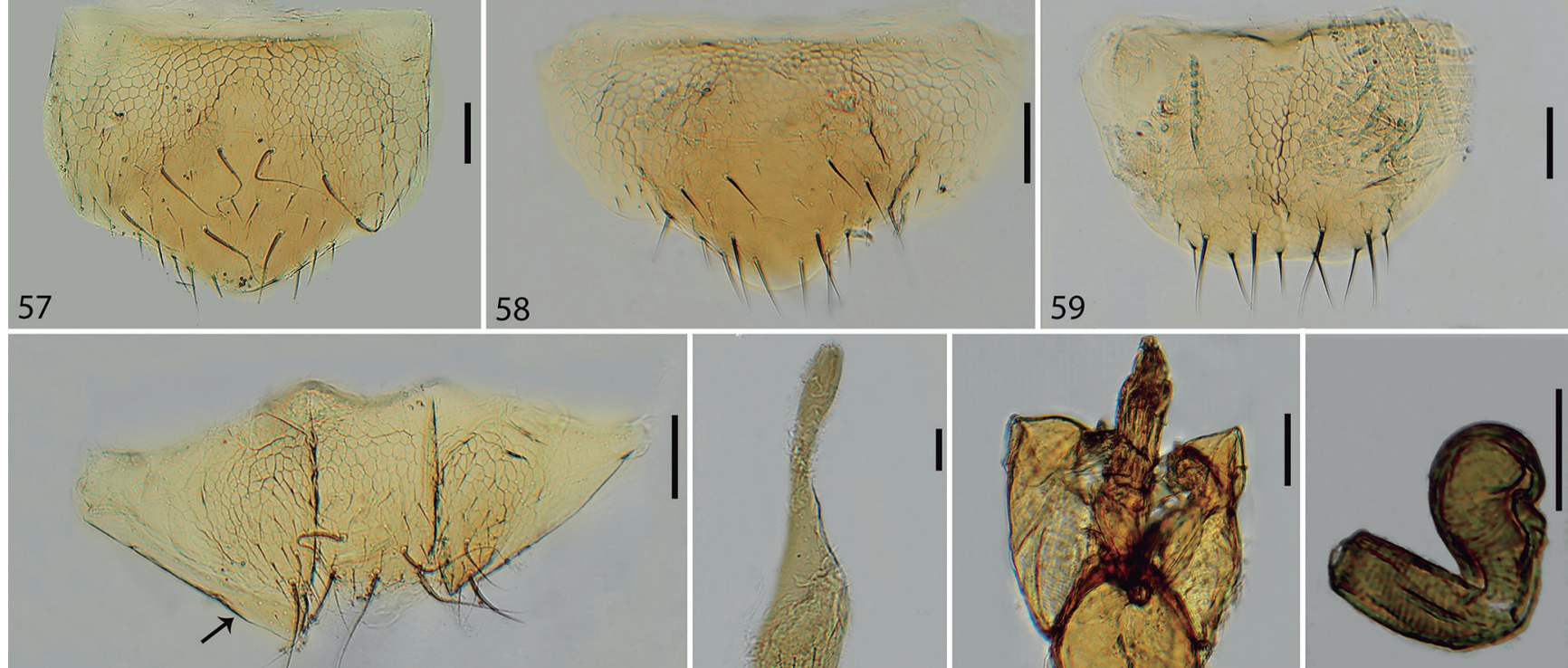

60
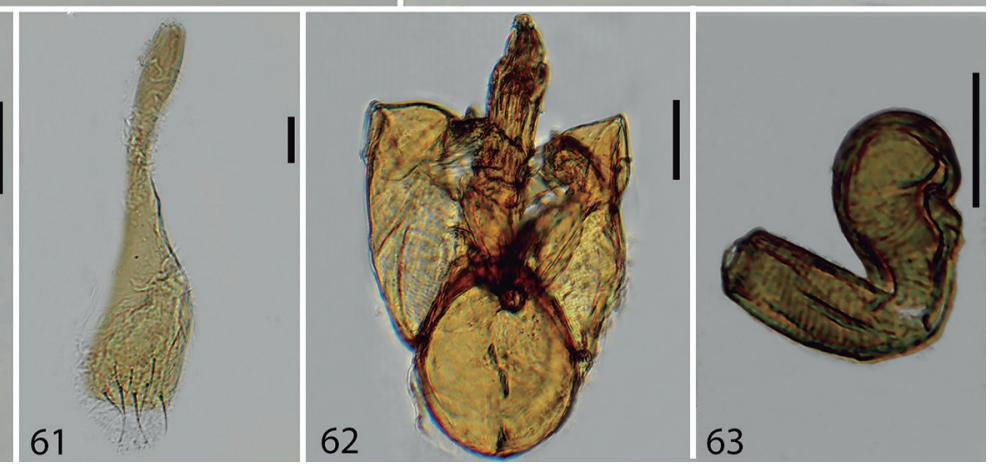

Figures 48-63. Fonsechellus heterosetosus sp. nov. (48A, B) mandible, right and left, arrows indicate teeth and drop shaped sulcus; (49) prementum; (50) maxilla; (51) labrum; (52) meso and metanotum; (53) meso and metasternum; (54) anterior leg; (55) median leg; (56) hind leg; (57) sternite VIII (female); (58) sternite VIII (male); (59) tergite VIII (male); (60) tergites IX and X (female), arrow indicating sternite IX; (61) sternite IX (male); (62) aedeagus; (63) spermatheca. Scale bars: $48,49,51=0.04 \mathrm{~mm} ; 50,52,63=0.05 \mathrm{~mm} ; 53=0.06 \mathrm{~mm} ; 55,57-62=0.07 \mathrm{~mm} ; 54=0.08 \mathrm{~mm} ; 56=0.15$. 
Fontes \& P.S. Terra col. (with Atlantitermes guarinim, MZSP 7830). PARATYPES: same data as holotype, 11 specimens (MZSP 21168).

Measurements: Length 1.5-1.8 mm (abdomen shrunk).

Diagnosis: Sclerotized parts reddish-brown; labrum not swollen; bristles on abdomen long on female and short in male; pronotum of female with 12 bristles, and male with four.

Description: Head almost as long as wide, widest right behind the eyes. Labrum transverse, about twice wider than long; not swollen in lateral view; $d 2-d 1 / m 2-m 1 / p 1$ present in male and female; three pairs of bristles present on the longitudinal-median region of labrum; first pair on posterior region absent in female (Figs. 51, 71). Mentum with four bristles each side, three primary bristles, near apex, long $(I)$, medium $(m)$ and short $(s)$, distributed as follows: I on antero-angular region, $s$ on central-apical of same transversal row, region; $m$ present behind and between / and s (Fig. 72).

Thorax: Pronotum with four primary bristles in male, two near anterior margin and two on disk near apex; discal bristles closer to each other than the anterior pair; 12 bristles in female, as follows: two pairs on anterior margin near apical angle, two pairs on either lateral margin, one subapical pair and another pair near base; elytra slightly
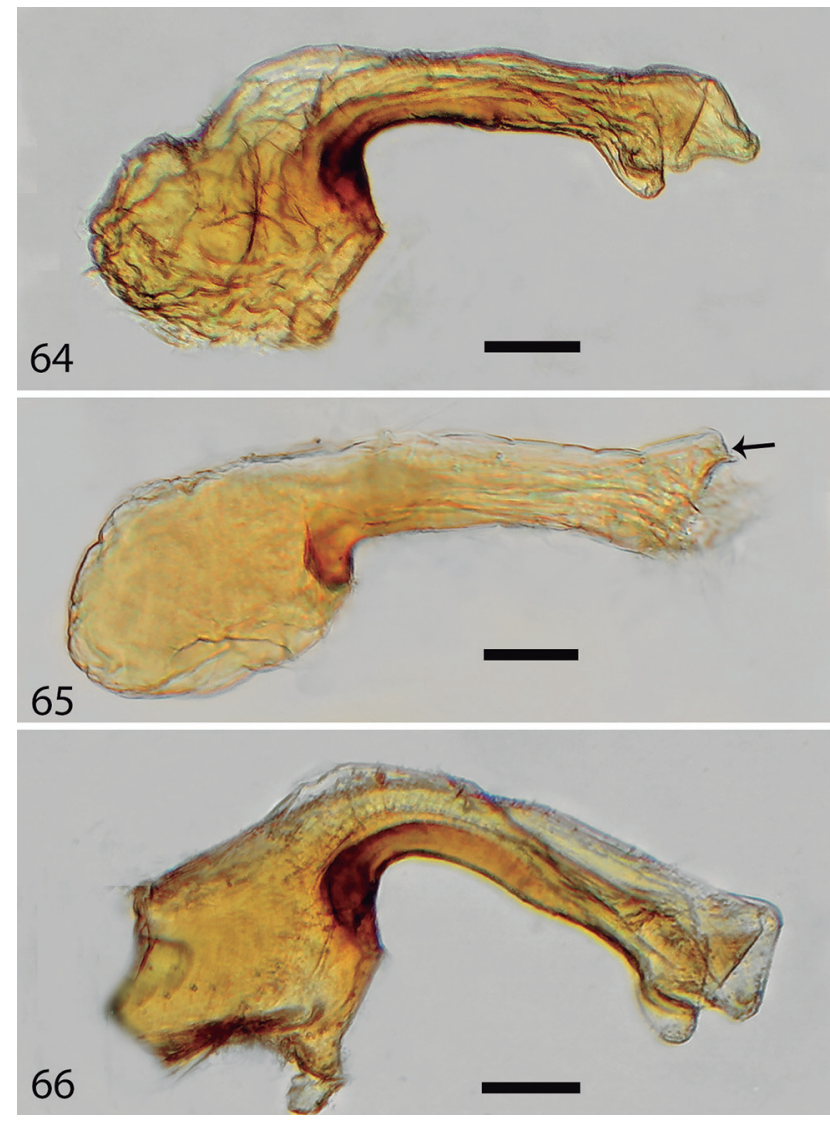

Figures 64-66. Median lobe. (64) Fonsechellus fragilis Seevers, 1957; (65) Fonsechellus fontesi Kistner, 1993, arrow indicating anterior projection; (66) Fonsechellus heterosetosus sp. nov. Scale bars: $0.05 \mathrm{~mm}$. elongate: considering the widest and longest measurements, it is about 1.3 times as long as wide.

Abdomen with bristles short in male and long in female (Figs. 44-47); tergite VIII with two pairs of transversally misaligned long bristles on median region (a2-a1) (slightly aligned in male), three pairs of medium bristles at apex (p3-p2-p1) (Fig. 59); sternite VIII with three pairs of transversally misaligned primary long bristles on median row and two long bristles centered below (Figs. 57-58); sternite IX in female divided into two slender portions attached to each margin of tergite IX (Fig. 60); sternite IX in male with apex enlarged, with four long bristles on apex and three shorter above (Fig. 61); tergite IX with many medium and short bristles, and one long and one very long bristle; tergite $X$ with two pairs of long bristles on each side and a central bristle of same size (Fig. 60). Aedeagus with median lobe apex not extended anteriorly on the dorsal region (Figs. 62, 66).
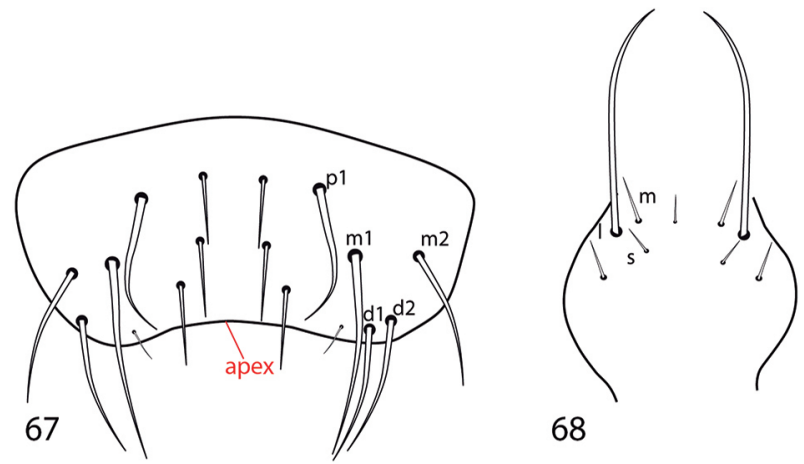

68

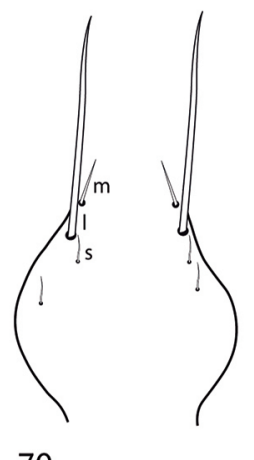

69

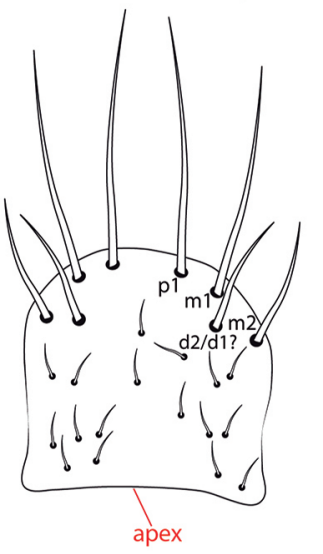

70

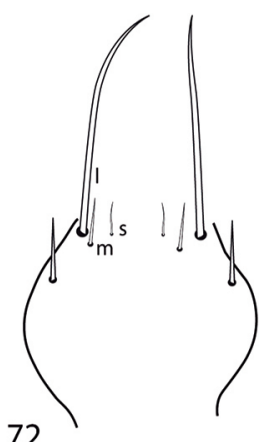

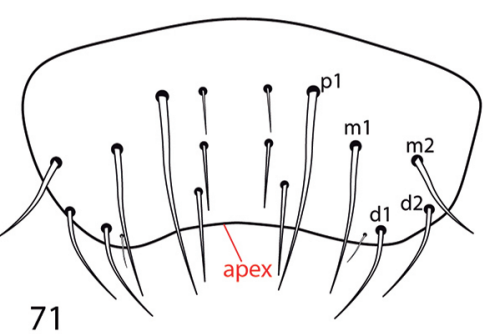

72

Figures 67-72. Chaetotaxy, schemes of labrum and postmentum. Fonsechellus fragilis Seevers, 1957: (67) labrum; (68) postmentum. Fonsechellus fontes Kistner, 1993: (69) labrum; (70) postmentum. Fonsechellus heterosetosus sp. nov.: (71) labrum; (72) postmentum. 
Etymology: The specific epithet is derived from the Greek adjetive "heteros" (different) plus the Latin substantive "seta", in allusion to the the sexual dimorphism related to different number and length of the bristles on pronotum and abdomen.

Host relationship: Associated with Atlantitermes guarinim Fontes, 1979.

Distribution: Known only from type locality: Itanhaém (Brazil).

Remarks: Similar to F. fragilis and F. bicolor. Distinguished from the former by the color of the sclerotized pieces, and the sexual dimorphism related to the length of the bristles on abdomen and the number of bristles on pronotum; and from the latter by the presence of non-geniculated clusters of bristles on the sixth segment.

\section{Further notes on wings condition in Fonsechellus species}

Loss of membranous wings in termitophilous beetles can be considered an expected event, even as a hindrance of the beetles within the nest (Zilberman, 2019).
This is observed in species of various genera in Corotocini and may become even more common as more taxa are studied in details. The process involved in wing detachment is not yet understood. The wings may be removed by the individual itself, or the individuals could induce termites to promote the removal. There are cases in some termitophilous species where the wings are not present in stenogastric forms. In this case, how do individuals disperse? In physogastric winged specimens, are the wings functional? These are issues beyond the scope of this paper, but it is worth noting the interesting case found in the Fonsechellus specimens studied here.

In the genus description, Silvestri (1946) mentioned the presence of well-developed wings and no case of broken wings in F. bicolor or F. diversicolor. Seevers (1957) also did not comment on species with this condition, and Kistner (1993) confirmed Silvestri's claim that wings are present and complete in species of the genus Fonsechellus. Except for the paratypes of F. fontesi, all specimens examined from the other studied species have broken wings. This means that the process of losing wings in Fonsechellus species is synchronized rather than stochastic. Possibly, specimens collected before the "right time" of wings removal will have them fully developed. Biological observations of these termitophiles are necessary in order to clarify such subject.
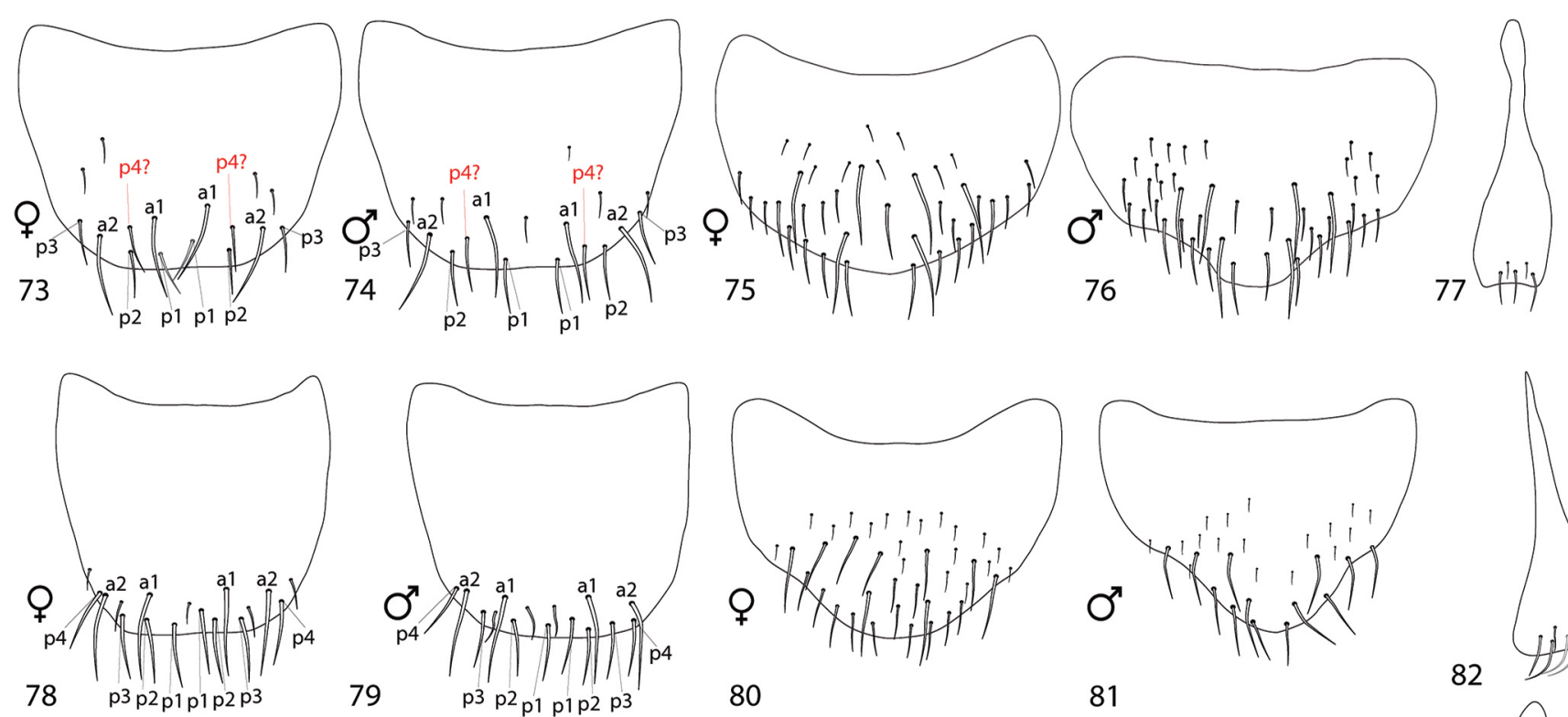

80

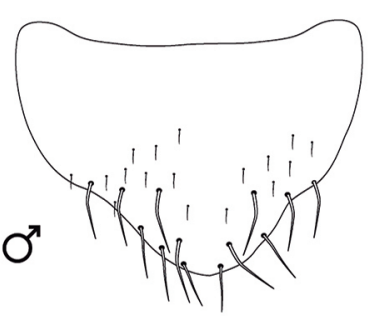

81
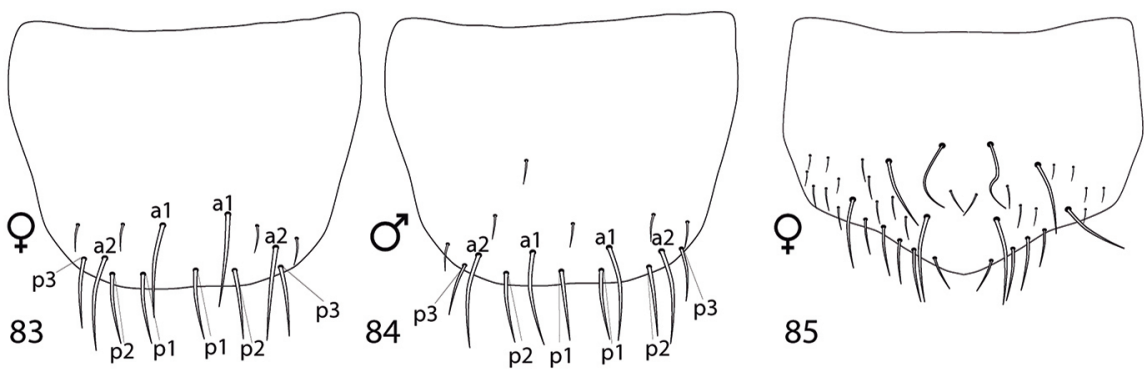

85

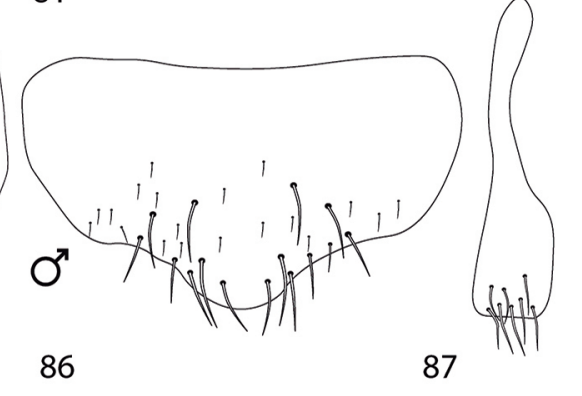

Figures 73-87. Chaetotaxy, schemes of tergites and sternites VIII and sternite IX. Fonsechellus fragilis Seevers, 1957: (73) tergite VIII (female); (74) tergite VIII (male); (75) sternite VIII (female); (76) sternite VIII (male); (77) sternite IX (male). Fonsechellus fontesi Kistner, 1993: (78) tergite VIII (female); (79) tergite VIII (male); (80) sternite VIII (female); (81) sternite VIII (male); (82) sternite IX (male). Fonsechellus heterosetosus sp. nov.: (83) tergite VIII (female); (84) tergite VIII (male);

(85) sternite VIII (female); (86) sternite VIII (male); (87) sternite IX (male). 


\section{Oecidiophilus Silvestri, 1946}

Oecidiophilus Silvestri, 1946: 331.

Type species: Oecidiophilus mimellus Silvestri, 1946, by monotypy (not O. oglobinii, nomen nudum, as originally designated by Silvestri, 1946).

Redescription: Head elongate, about 1.4 times as long as wide, not widest behind the eyes; gula narrow, lateral margins almost parallel; foramen magnum broad, about one third the head width; mandibles symmetrical; maxillary palpi with 4 palpomeres, fourth palpomere almost the length of the third; prementum with palpi with 3 palpomeres, and ligula slightly incised in the middle; antennae with 11 antennomeres, scape as long as antennomeres II and III combined, III-X slightly longer than wide, progressively and slightly decreasing in length towards apex.
Thorax: Wings present and broken; first metatarsomere as long as second and third combined.

Abdomen highly physogastric and scarcely setose, covered mostly by short and medium bristles; tergite IX without macrosetae; tergite $X$ suboval, with midsized bristles at apex. Aedeagus with phallobase large and bulbous, apex of median lobe with membranous structure with sinuous pattern.

Remarks: The genus Oecidiophilus until now was represented by a single enigmatic species from Argentina, Loreto (Misiones), known only from the holotype and the original description (Silvestri, 1946). Herein, the second species of the genus is described, representing the first record of Oecidiophilus for Brazil. The wings of the analyzed specimen were broken in a similar way to that found in Fonsechellus species. It is presumed that individuals lose their wings in the same way as Fonsechellus and

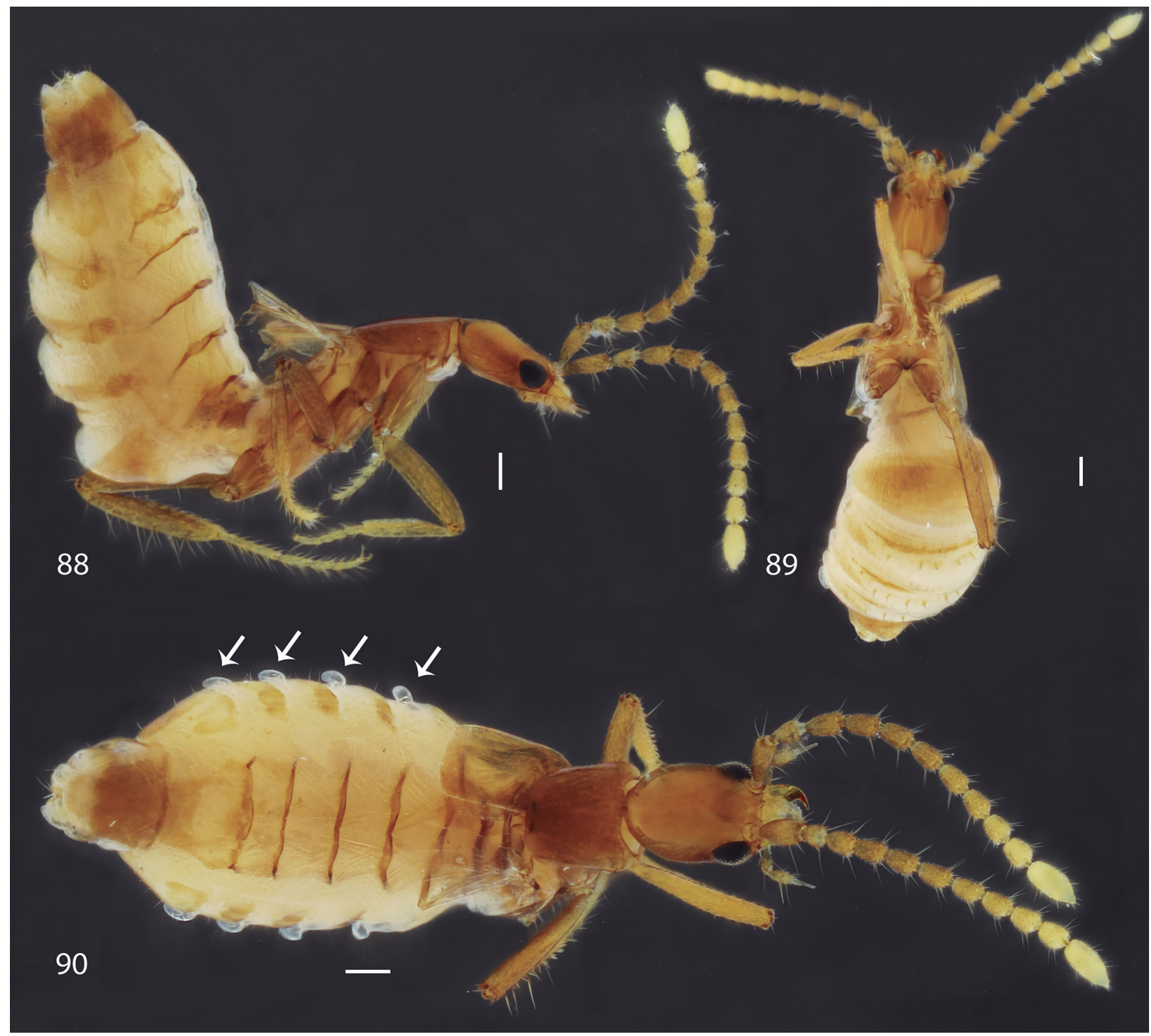

Figures 88-90. Oecidiophilus cleidecostae sp. nov. Holotype (male). Habitus: (88) lateral; (89) ventral; (90) dorsal, arrows indicating glandular sacs on abdomen. Scale bars: $0.1 \mathrm{~mm}$. 
it would not be impressive if this phenomenon was even more embracing across other related genera in the subtribe Termoiceina.

\section{Oecidiophilus cleidecostae sp. nov. (Figs. 88-94)}

Type material: HOLOTYPE $\sigma^{7}$ (MZSP 21174). BRAZIL. Minas Gerais: Belo Horizonte, 29.vii.1975, Renato L. de Araujo col. (with Diversitermes sp., MZSP 6171).

Measurement of Holotype: Length $1.9 \mathrm{~mm}$ (abdomen partially extended).

Diagnosis: Abdomen highly physogastric, with light reddish-brown pronotum and head; abdomen bearing glandular sacs on lateral margins; body scarcely setose, including sclerotized parts; secondary sclerotization poorly developed, with tergite and sternites mostly represented by tiny sclerotized bands.

Description: Abdomen highly physogastric, with sternites and tergites poorly developed, leaving mostly tiny sclerotized bands visible on dorsal and ventral views; sides of segments IV-VII bearing conspicuous glandular sacs; last tergites and sternites scarcely setose (Figs. 88-90); tergite VIII wider than long, with one pair of primary bristles distanced from each other on median row, and another pair of apical bristles close to each other, below anterior ones (Fig. 91); sternite VIII wider than long, with a pair of distant bristles medially and two pairs below, apically (Fig. 92); tergite IX trapezoidal, without macrosetae; sternite IX (male) slender, slightly enlarged toward apex, without macrosetae (Fig. 94). Tergite X suboval, with four bristles at apex (Fig. 93). Aedeagus with phallobase enlarged, lateral lobes structurally complex, divided into distal, median and proximal pieces (Fig. 97); median lobe with apex with three rows of sinuous membranous lobes (Figs. 95, 96).

Etymology: The specific epithet is patronymic, in honor of the great entomologist Dr. Cleide Costa, from Museu de Zoologia da Universidade de São Paulo (MZSP).

Host relationship: The termite nest sample MZSP 6170 where the beetle was collected included species of Diversitermes Holmgren (Nasutitermitinae),
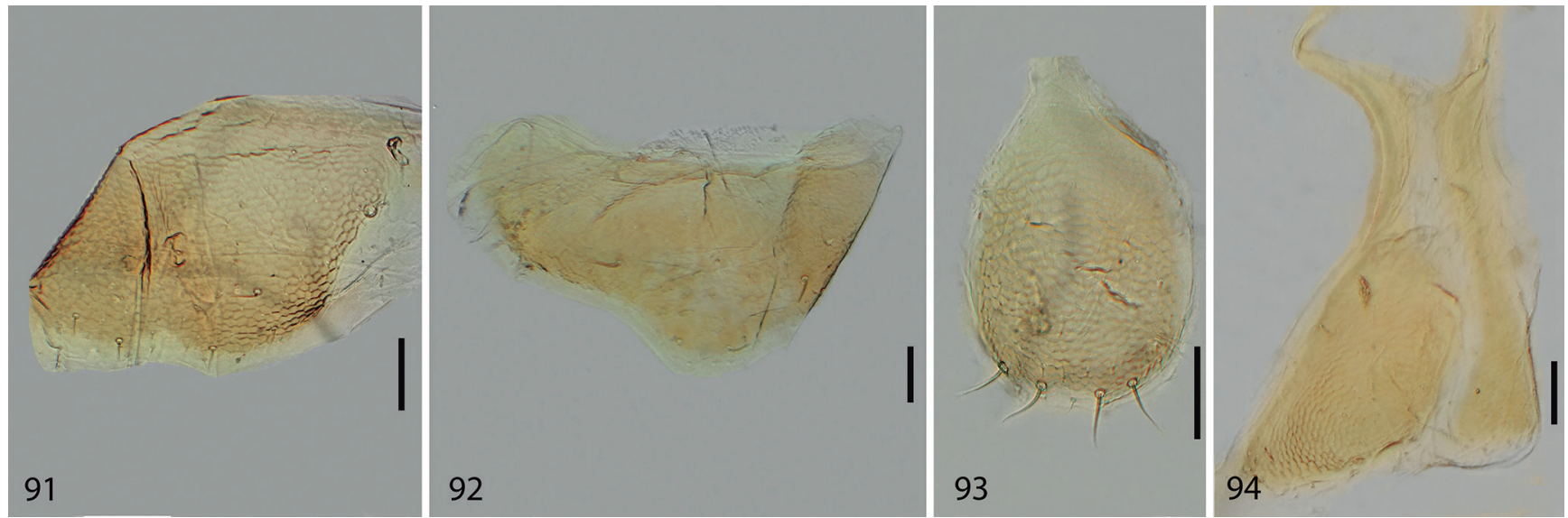

Figures 91-94. Oecidiophilus cleidecostae sp. nov. Holotype (male): (91) tergite VIII; (92) sternite VIII; (93) tergite X; (94) tergite and sternite IX. Scale bars: 0.05 mm.

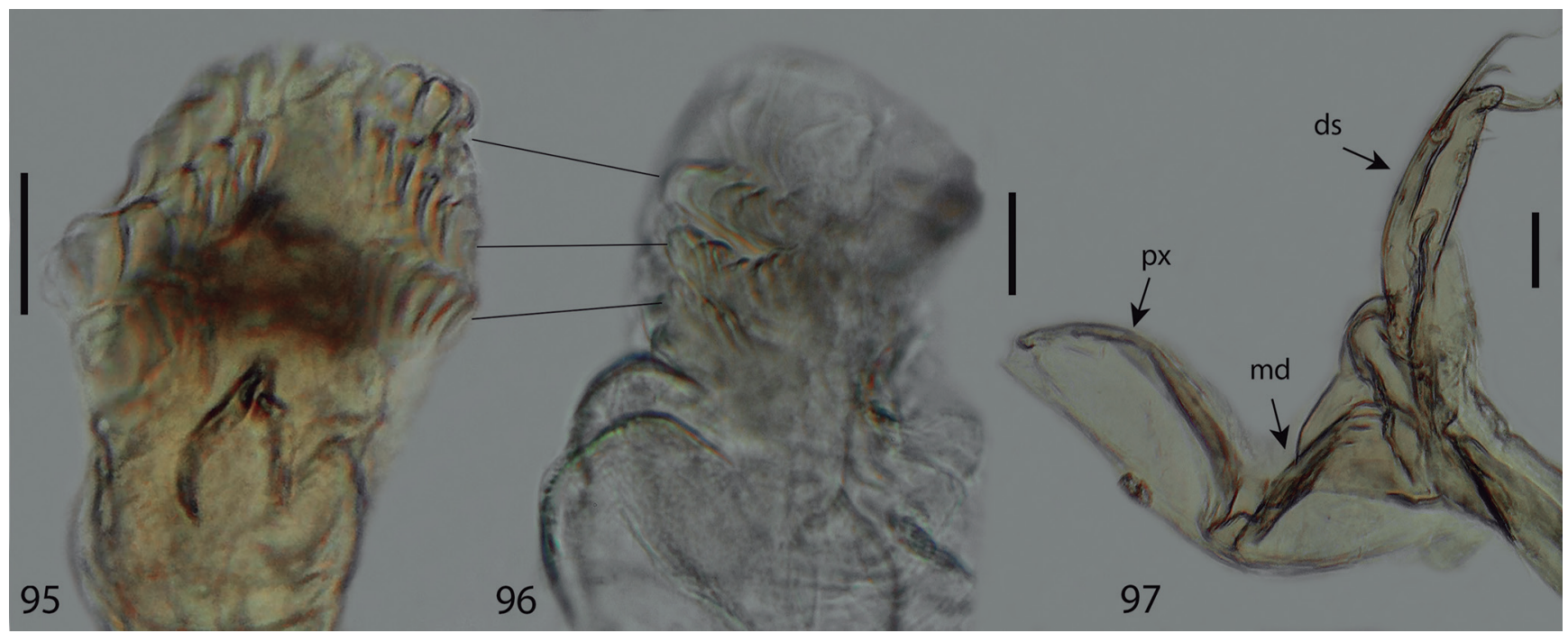

Figures 95-97. Oecidiophilus cleidecostae sp. nov. Holotype (male), aedeagus: (95) median lobe apex, dorsal; (96) median lobe apex, lateral; (97) lateral lobe. $\mathrm{ds}=$ distal; $\mathrm{md}=$ median; $\mathrm{px}=$ proximal. Scale bars: $0.02 \mathrm{~mm}$. 
Spinitermes Wasmann (Termitinae), Syntermes Holmgren and Labiotermes Holmgren (Syntermitinae). It is unlikely that any of the last three were the host of Oecidiophilus cleidecostae sp. nov. The host is most likely Diversitermes sp., which is also congruent with O. mimellus host information (Silvestri, 1946).

Distribution: Known only from type locality: Belo Horizonte (Brazil).

Remarks: The shapes of the head and thorax of Oecidiophilus cleidecostae sp. nov. resemble those described for the genus. The chaetotaxy, however, seems to be different between the species. These features can be properly described and confirmed when additional specimens become available for dissection.

Four conspicuous morphological features easily differentiate the two known species (O. mimellus in parenthesis): the sclerotized portions are reddish-brown (straw-colored); the tergites are represented only by tiny sclerotized bands (seem to have developed secondary sclerotization); paratergites slender (wide); sides of the abdomen with glandular sacs (glandular sacs absent). Two less conspicuous morphological features of male genitalia differentiate the new species: the lateral lobes are divided into three parts (proximal, px; median, md; distal, ds) and not two, as in O. mimellus (proximal and distal); the apex of the median lobe has three rows of sinuous and membranous lobes, while in O. mimellus there is only one (see Silvestri, 1946, figs. 17-18).

\section{ACKNOWLEDGMENTS}

The first author thanks Coordenação de Aperfeiçoamento de Nível Superior (CAPES) for the financial support. We thank the referees and editors for carefully reading and for giving constructive suggestions which substantially improved the quality of the paper.

\section{REFERENCES}

Jacobson, H.R.; Kistner, D. \& Pasteels, J.M. 1986. Generic revision, phylogenetic classification, and phylogeny of the termitophilous tribe Corotocini (Coleoptera: Staphylinidae). Sociobiology, 12: 1-245.

Kistner, D.H. 1993. A redescription of the genus Fonsechellus with a description of a new species from Brazil associated with Araujotermes (Coleoptera: Staphylinidae; Isoptera: Nasutitermitinae). Sociobiology, 23(2): 199-209.

Sawada, K. 1972. Methodological research in the taxonomy of Aleocharinae. Contributions from the Biological Laboratory Kyoto University, 24(1): 31-59.

Seevers, C.H. 1957. A monograph on the termitophilous Staphylinidae (Coleoptera). Fieldiana: Zoology, 40: 1-334. D0I

Silvestri, F. 1901. Descrizione di nuovi termitofili e relazioni di essi com gli ospiti. Bollettino del Musei di Zoologia ed Anatomia comparata della Università di Torino, 16(398): 1-24.

Silvestri, F. 1946. Descrizioni e notizie di Staphylinidae termitofili sudamericani. Commentationes Pontificia Academia Scientiarum, 10: 299-334.

Zilberman, B. 2018. New species and synonymy in the genus Corotoca Schiødte, 1853 (Coleoptera, Aleocharinae, Corotocini). Zootaxa, 4434(3): 547-560. DOI

Zilberman, B. 2019. Synopsis of the genus Termitozophilus Silvestri (Coleoptera, Staphylinidae, Aleocharinae, Corotocini). Zootaxa, 4614(1): 95-116. D0I 